\title{
Challenges Faced by Disabled Students in Online Learning during the COVID-19 Pandemic
}

Sheela Paramasivam, Isai Amutan Krishnan, Aizan Sofia Amin, Narentheren Kaliappen, Randeep Singh Sidhu, Hoviyashree Anbalagan

To Link this Article: http://dx.doi.org/10.6007/IJARBSS/v12-i1/12282

DOI:10.6007/IJARBSS/v12-i1/12282

Received: 20 November 2021, Revised: 30 December 2021, Accepted: 15 January 2022

Published Online: 29 January 2022

In-Text Citation: (Paramasivam et al., 2022)

To Cite this Article: Paramasivam, S., Krishnan, I. A., Amin, A. S., Kaliappen, N., Sidhu, R. S., \& Anbalagan, H. (2022). Challenges Faced by Disabled Students in Online Learning during the COVID-19 Pandemic. International Journal of Academic Research in Business and Social Sciences, 12(1), 2098-2113.

Copyright: (c) 2022 The Author(s)

Published by Human Resource Management Academic Research Society (www.hrmars.com)

This article is published under the Creative Commons Attribution (CC BY 4.0) license. Anyone may reproduce, distribute, translate and create derivative works of this article (for both commercial and non0-commercial purposes), subject to full attribution to the original publication and authors. The full terms of this license may be seen at: http://creativecommons.org/licences/by/4.0/legalcode

Vol. 12, No. 1, 2022, Pg. 2098- 2113

Full Terms \& Conditions of access and use can be found at http://hrmars.com/index.php/pages/detail/publication-ethics 


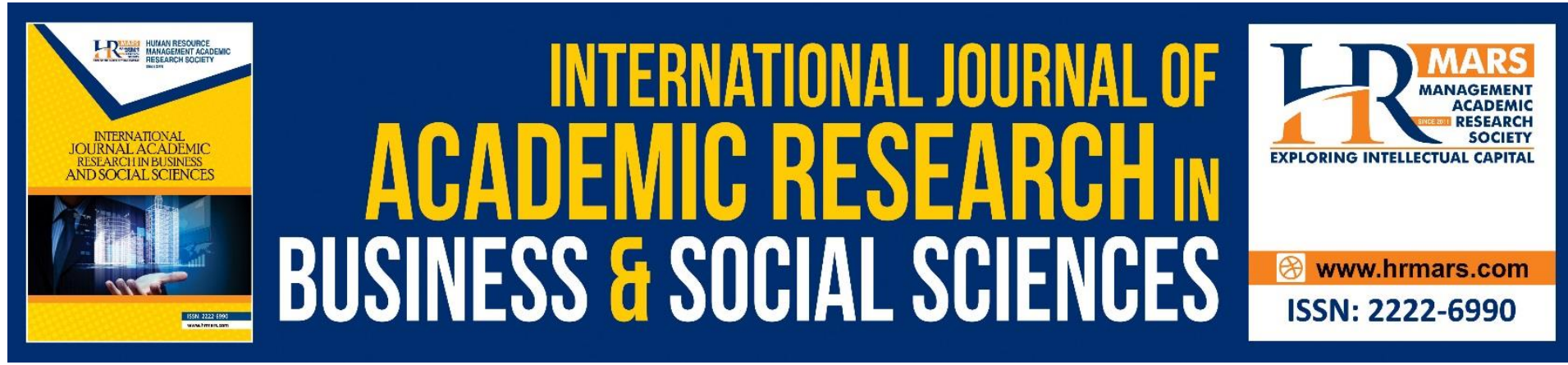

\title{
Challenges Faced by Disabled Students in Online Learning during the COVID-19 pandemic
}

\author{
Sheela Paramasivam \\ Universiti Teknologi MARA, Seremban, Negeri Sembilan, Malaysia
}

Isai Amutan Krishnan

Perdana University, School of Liberal Arts and Science and Technology

Email: isai.amutan@perdanauniversity.edu.my, amuthan.isai@gmail.com

\begin{abstract}
Aizan Sofia Amin
Centre for Research in Psychology and HumanWell-being, Faculty of Social Sciences and Humanities, Universiti Kebangsaan Malaysia (National University of Malaysia).

Email: aizansofia@ukm.edu.my
\end{abstract}

Narentheren Kaliappen

School of International Studies, University Utara Malaysia

Email: narentheren@uum.edu.my

\section{Randeep Singh Sidhu}

Perdana University, School of Liberal Arts and Science and Technology

Email: randeep@perdanauniversity.edu.my,randeeproy89@yahoo.com

\section{Hoviyashree Anbalagan}

Wembley Academy

Email: hoviyashree.anbalagan@gmail.com

\begin{abstract}
The Covid-19 pandemic has brought changes to the scenario of teaching and learning in schools and higher institutions of education. The shift from face-to-face traditional mode to online platforms has brough many challenges along with it. This 'new norm' of pedagogy has also posed challenges to disabled students in higher learning institutions across Malaysia especially when using online platforms to study. Therefore, the purpose of this study was to investigate the mental and emotional challenges and learning problems faced by disabled students in online classes during the current pandemic. Fifteen disabled students of various disabilities from universities participated in the study. Semi-structured interviews were employed to interview the participants and the collected data was analysed qualitatively using the self-determination theory. The findings showed that most of the disabled students
\end{abstract}


faced mental stress challenges as they were not familiar with Skype, Zoom and Google Meet. They were also not familiar with modern electronic and sophisticated gadgets. The findings further revealed that disabled students were not ignorant in their learning and their disabilities were not obstacles to excel in education. However, they do need help to overcome their fears and challenges. The present study hopes that higher learning institutions assign special task force to facilitate disabled students. The task force should recognise the prospective requirements of disabled students plan and carry out counselling to provide fundamental preparations for online learning. These measures would better prepare them physically and mentally to face unpredictable challenges in the future.

Keywords: Challenges, Disability, Disabled Students, Online Classes, Learning

\section{Introduction}

The effects of coronavirus have been felt by everyone ever since it was declared as a global pandemic by the World Health Organization (WHO) in January 2020. Consequently, the Malaysian Government issued a Movement Control Order (MCO) as a precautionary measure against the pandemic. At that time, there were approximately 80,000 Malaysian students on campus nationwide excluding those who stayed outside when the MCO was announced. The implementation of MCO leads to the restructuring of the education system, right from elementary level to tertiary level. This move affected educational institutions that relied on traditional, face-to-face learning (Ahmad et al., 2020). Although many universities have started utilising blended learning platforms, many of them are still bound and tied to traditional teaching methods.

In response to the MCO, the Ministry of Higher Education (MOHE) requested all the Institutes of Higher Education both public and private, to streamline their teaching process for effective online learning via the Internet (Bernama, 2020). The MCO has seriously affected a large number of educational programs although several learning activities have continued via an online medium (Bernama, 2020; Awani, 2020). Some university managements requested their lecturers to apply synchronous and asynchronous teaching methods for all the students (Tan, 2021).

Lim (2020), a media reporter, stated that online learning has become the 'new norm' today, where university students are required to attend online classes. This situation has posed a challenge to students with physical and mental disabilities. In line with Lim (2020), Rayyan (2020) also reported that being afflicted with some disabilities, these students endure various mental challenges owing to different online classes that have been introduced by educational institutions. These may create problems that need to be solved so that the disabled students are not left behind in terms of their educational requirements (Abdullah et al., 2020). There is another problematic issue - face-to-face instructions have been replaced by online teaching. There are many disabled students from the lower income groups in Malaysia who are unable to acquire sophisticated gadgets needed to participate in online learning. Based on these problems, the physically disabled students have a greater propensity to feel stressed during this period of uncertainty and face mental challenges (Bernama, 2020). The security and welfare of all students needs to be given due consideration for them to excel in their education. The time has arrived for the authorities, staff and students to accept the circumstances and find pragmatic solutions. Therefore, the purpose of the present study is to investigate the mental health challenges faced by disabled students from public universities when exposed to online learning during the current pandemic. 


\section{Literature Review \\ Self-Determination Theory}

The self-determination theory (SDT) (Deci \& Ryan, 1985; 2000) states that humans are compelled to continuously develop and improve from a psychological perspective. The SDT theory has been divided into four categories; namely; cognitive evaluation, organismic integration, causality orientations, and basic needs. Through extensive studies, the SDT is linked to the mental and physical states of a person. This theory also says that humans have three psychological needs for their well-being: competence, relatedness and autonomy, as shown in Table 1.

Table 1: Definitions of SDT Theory

\begin{tabular}{cll}
\hline NO & \multicolumn{1}{c}{ CATEGORIES } & \multicolumn{1}{c}{ DEFINITIONS } \\
\hline 1 & Cognitive Evaluation & $\begin{array}{l}\text { The effects of the surroundings and social } \\
\text { situation in reducing intrinsic motivation. }\end{array}$ \\
2 & Organismic Integration & $\begin{array}{l}\text { How people become more eager as they } \\
\text { begin to adapt to an activity }\end{array}$ \\
3 & Causality Orientation & $\begin{array}{l}\text { Differences in humans when they have } \\
\text { self-determined behaviour. }\end{array}$ \\
4 & Basic Needs & $\begin{array}{l}\text { The psychological needs of humans for a } \\
\text { healthy development of mental state. } \\
\text { Autonomy, competence and relatedness. }\end{array}$
\end{tabular}

Source: (Deci \& Ryan, 1985; 2000)

Table 1 shows the categories of SDT theory. The SDT tells us that we need to be in a good physical and mental state to develop self-determination. The SDT has also been shown to affect a person's motivation to maintain good oral hygiene.

There were several recent studies conducted pertaining to the SDT. Chiu and Thomas (2021) conducted a study on the student engagement in K-12 online learning during Covid19. It was found that technological aid strategies can satisfy students' needs better than normal means. Another study conducted by Sobia et al (2021) reported that although the study environment of a student does not directly affect the academic progress of students, it has been proven to affect their psychological state and cause them to worry. This indirectly contributes to the decline in their mental health as well as studies. A similar study was conducted by Holzer, Lüftenegger,Korlat, Pelikan, Salmela-Aro, Spiel and Schober (2021). The findings revealed that to promote personal development, the well-being of one's mental state as well as basic satisfaction needs have to been taken into account and increasingly promoted from an educational perspective. Another study pertaining to the SDT was conducted by Chu et al (2021) and it was reported to be successfully applied across a wide variety of situations and had led to better outcomes. Several scholars have also reported that better motivation 
will result in better outcomes, thus, making learning a more approachable activity. Yet another study conducted by Al-Kumaim et al (2021) revealed that one can improve mental health and increase self-motivation by fulfilling autonomy, competence, and relatedness. On the contrary, it has been observed that an individual's well-being is affected negatively when these conditions are not fulfilled.

The above studies have concluded that one both mental health and the learning environment are both critical factors of self-determination and productivity and should not be ignored. Even with the onslaught of the Covid-19 pandemic being an obstacle, these concerns need to be addressed especially among disabled students who face technological and space constraints to ensure to ensure that teaching and learning continues as normal..

\section{Past studies Pertaining to Online Learning}

Past research on online learning directed towards the incorporation of Information and Communication Technology (ICT) in teaching, indicate that teachers and students have very little awareness of technology and handling of equipment (Ziadat, 2019).

Throughout this period, instructional processes linked to more modern technology have been set up and included in the dynamic teaching systems (Venezky \& Davis, 2002). Many investigations on the suitability of instructional methods, and the personalities of students who benefit from online studies have been undertaken (Fuller et al., 2000; (Lockee, 2001). The findings show that the type and degree of achievement attained through online learning for students with disabilities is difficult to quantify. Scholars agree that students taking online lessons have to be capable of self-education, are matured and well-disciplined, highly motivated in mind and body, capable of expressing and communicating through writing, and committed to meet deadlines (Leasure et al., 2000). The students should also be skilled in managing an online learning environment (Buchanan, 1999; Diaz \& Cartnal, 1999; Trentin, 2002).

Students with learning disabilities are a frequently mentioned group as each person is special and different. Nevertheless, despite having various disabilties, many disabled students have some common ground in terms of behaviour. They show reduced incentive to study, are less proficient in studying, require assignments to be divided into smaller parts, encounter difficulties in simplifying, and lack analytical skills and objectivity (Cavanaugh et al., 2009). Moreover, Cavanaugh et al (2009) indicated more enhancements in objectivity, computer skills, self- education, decision making, creativity, interpersonal skills, and prioritizing skills of students with disabilities as important for disabled students compared to normal students in conventional classroom surroundings. Surprisingly, studying online does create some difficulties in students' education while at the same time provides many advantages.

Past studies have shown negative influences of the pandemic on the psychological health of students, the most common being acute depression and anxiety (Coa et al., 2020). According to a report released by the United Nations Educational, Scientific and Cultural Organization (UNESCO), the pandemic severely interrupted one billion students in a hundred and twenty-nine countries. Studies conducted in China at the height of the pandemic revealed that out of the 7143 students, $0.95 \%$ had severe anxiety and depression, $2.7 \%$ had moderate anxiety and depression and $21.3 \%$ suffered mild depression. This study revealed the impact of the pandemic on students. Another study by UNESCO (2020) on 1210 Chinese students from 194 cities in China revealed that $53.8 \%$ had developed moderate psychological problems and that female students were more affected than the male students. 
Their living conditions and educational methods had changed drastically and caused emotional stress, loneliness, and depression (Sundrasen et al., 2020). In another study conducted by Loheswar (2020) on Malaysian university and college students, findings revealed that $50 \%$ of them had encountered negative mental health that ranged from anxiety, depression, stress and even mild forms of hallucinations. They further mentioned that the lockdown and MCO affected the socio-psychological conditions of the students. The Ministry of Higher Education announced on the $27^{\text {th }}$ of May, 2020, that all public and private HLEs conduct all their classes online. This announcement had a serious impact on students with learning difficulties, especially for the disabled. The sudden onset of the pandemic has created a paradigm shift in the learning and teaching approaches. The immediate introduction of online classes caused significant challenges to lecturers and students both to the normal students and the disabled. Students struggled at this period of time as they had to cope with more assignments. It has been stated by Yap (2020, cited in Lim, 2020) that there was little opportunity for students to interact directly with their lecturers. As all forms of physical interactions were strictly forbidden, audio and video were used to deliver lectures. As reiterated by Yap (2020), poverty and bad Internet connectivity at times disrupted lectures and the students were left in a difficult and helpless predicament. As a result of the unreliable Internet services, student's engagement in group discussionswas seriously affected. The inability of the students to cope with online teaching, made many of them experience psychological problems like anxiety, depression, lack of focus and concentration. Studies conducted on Malaysian students revealed many of them had developed memory and visual motor skills problems (Wang et al., 2020).

To date several studies have been conducted on the effects of the pandemic in China and other Western countries and on the general population, health care workers and even on medical students. However, there is lack of studies conducted on the predicament of the disabled students. As such, this study aims to explore challenges faced by disabled students in online learning. Findings of this study can add to the existing literature.

\section{Methodology}

The present study employed a qualitative method (Creswell, 2018). Consents were obtained from the participants in order to conduct this study via students' affairs departments in the respective universities. Creswell (2018) noted that for the qualitative studies 5 to 25 participants would be sufficient. Therefore, fifteen disabled students participated in the study, and they were selected purposively based on the objectives of the study. They were aged between 23 and 26 years old, of mixed races and gender and from the social sciences and humanities courses. The students were from a few public universities such as University Malaya (UM), Universiti Kebangsaan Malaysia (UKM), Universiti Teknologi MARA (UiTM). These universities are located in Klang Valley, Kuala Lumpur, Malaysia. The disabled students have different types of disabilities such as attention-deficit hyperactivity disorder (ADHD), Attention deficit disorder (ADD), Cerebral Palsy (CP) and visual impairment. In general, they are disabled physically and mentally.

The data were collected via semi-structured interviews. The semi-structured interview questions were adopted and modified from the study by Krishnan et al(2020) and modified as per the objectives of the study (Miles \& Huberman, 1994). The interview was conducted in English language via ZOOM as there were no F2F or physical communication done during this period of the Covid19 pandemic. It was determined that ZOOM was used as the medium of communication between the researchers and the interviewees as ZOOM is a cost-effective 
and safe way to contact each other without needing to risk being exposed to the virus. In addition, ZOOM offers a conversation recording feature that is extremely useful for the researchers to keep the recording for further reference. Each recording was about 10-12 minutes.

In addition, in-depth interviews were conducted via ZOOM with five lecturers, three CEO of Education and five parents in the study to triangulate the findings. They were selected based on purposive sampling (Creswell, 2018) and on the objectives of the study. The purpose of the in-depth interview was to investigate and identify the different levels of difficulty, in terms of mental health and learning challenges during online learning, faced by these demographics so that the universities or other organisations would be able to provide assistance to these disabled students.

The recorded data were transcribed and categorised based on the Self-determination theory (Deci \& Ryan, 1985, 2000). Then, the data were coded in NVIVO. Abbreviations were used in this study for students (S1), lecturers (L), chief executive officer (CEO) and parents (P) for the analysis purpose.

\section{Analysis and Discussion}

\section{Analysis based on Self-Determination Theory}

There were several mental health challenges encountered by the disabled students as indicated below:

1. isolation

2. emotional setback

3. exacerbated mental health

4. anxiety without knowing the identity of lecturers

5. lack of confidence to attend online classes.

\section{Isolation}

S2 '...I was born with visual impairment and I was brought up with only four senses such as touch, hear, smell and taste. The only happiness I found was when I went to university and heard noises from my friends. After the announcement of the lockdown all the classes were conducted online, I could just feel the air and I felt the isolation...'

S3 '... I am not happy with the online classes and I am isolated...'

S4 '...only god knows the pain of isolation...'

$S 5$ '...I am dumbfounded with the feeling of isolation ...'

S10'... am happy to hear what the lecturers said but I can't see the class which is no issues. However, with online classes there is no physical contact. I feel less motivated and isolated and I am easily demoralized...'

From the above utterances, it was found that the disabled students had been badly affected by the pandemic. The prevalent emotional feeling among them was isolation and this had affected them in different ways. They had lost contact with their friends and their lecturers, and this had deprived them of the essential educational support they had received from them. 
The temporary suspension of the normal classes added to their misery as they could not meet anyone to discuss their problems.

\section{Emotional Setbacks}

S1'...first of all, I am emotionally affected. How was thinking how the online class would be as I am disable student. I am not afforded to use expensive gadgets. This is really ruined me very much...

S2 '... feeling stressed with online, I am having hearing impairment and the aid which I use is not really helpful, I got a headache, I am feeling emotionally weak and I am afraid of the exam. I also feel demotivated. Not familiar with those ZOOM, Microsoft team and other teaching tools. Unable to comprehend in the instruction to access those tools. Mentally and physically affected as well as emotional...'

S6 '... I can't access the internet and am not familiar with ZOOM, Skype. It is really tough for me. I can't even hear and talk. How? I do not know what to say sir. I am emotionally affected and no one can understand my struggles...'

S11'... I am about to complete my studies and I feel angry and frustrated...I planned to graduate from my studies in October. My classmates said 'I did my homework in three hours,' and I thought, 'Lucky you. I had to obtain this document and find it in a usable format and struggle harder because of the added time. This gives me depression and I am having an unstable mind...hmmm emotionally...I feel like to cry....'.

$S 15$ '...I am not really happy as the internet connection is very poor as I stay in a rural area. I feel online teaching for disable student is very expensive and you must a good at smart phones. Actually, my family not afford to buy. I have no choice and I did not attend the online classes and this causes stress and depress and I am emotionally unstable and easily get angry nowadays...'

It appears that the disabled students were suffering from immense mental stress that caused emotional disturbance. The underlying reason for this distressful state was mainly because they were unfamiliar with the introduction of computer technology when the online classes began. The disabled students had to familarise themselves with the technology in a very short period of time with new systems like Zoom and Microsoft Team used to conduct online classes.

Those who had vision problems had to spend more time getting adjusted to these new learning systems. At the same time, they had to spend more time completing their assignments. As most of them were not financially stable, the introduction of online classes forced them to buy new smart phones to follow the online classes. The emotional stress had seriously affected their educational achievement.

\section{Exacerbated Mental Health}

S3'...since I have issues with paying close attention in class, I have been contemplating the option of online learning ever since my first semester. But I never thought about it being a real possibility until the onset of the pandemic. Autistic people like me were highly responsive to sound, which could prevent them from focusing on their lesson...' 
S4'...I face self-stigma and difficulties learning through the online system. And I am not familiar with online platforms. My parents are not rich enough to buy smart gadgets...'.

S8 '...I suffer from muscle coordination problems and mentally ill. I am not sure how I am going to cope with the online classes...'

S12 '...I have some mental illness and can't understand easily and the online classes are not helping me...'

S14 '...I was born with a cleft lip and mental illness. When the university informed me that the semester would carry on through open and distance learning (ODL), I was devastated and I told myself that this does not work...'

$S 15^{\prime} . . . I$ have undergone mental illness remedies recently and for me online learning is certainly not suitable...'

From the above utterances, it was found that those with mental problems were also affected by the new system of online learning. They found difficulty to cope with online classes as they had different mental illnesses that hampered their educational progress. They had become more stressed now because of the new system that demanded more attention than before. With limited help from friends, their emotional plight became severe.

This is different from emotional setbacks faced by the students, as this does not only involve the emotional state of the disabled students, but also their willingness and ability to cope with the new demanding learning environments. Ultimately, these students felt unmotivated and uninspired to persist learning and take part in online discussions.

\section{Feelings of Anxiety Not Knowing The Identity of Lecturers}

S4 '... I do not know who my lecturer is and I would like to know his/her background. I feel nervous and anxious without knowing who my lecturer is...'

S9 '... How do you feel when you know your parents but did not appear in front of you and the same goes to the lecturer. I wanted to know the identity of my lecturer...'

S12 '...actually I feel disconnected without knowing the traits of the lecturers and it ruins me...'

S13 '... felt uncomfortable to ask questions without knowing my lecturer well even though the ice-breaking session was done...'

S14 '...I ...am psychologically impacted without knowing the person...'

The results showed that the disabled students faced anxiety because of their lack of contact with their lecturers. The development of the online classes had created a barrier for the disabled as they could not contact them freely to clear their doubts or discuss their difficulties. This problem had caused anxiety that had stressed them immensely. The disabled felt that 
the lack of contact with the lecturers had psychologically affected them and had adversely impacted their progress.

However, this was not the only source of the students' anxiety. Students also felt anxious when thinking about how to further their studies and what to do after they graduate, especially during the Covid-19 pandemic. Furthermore, the intermittent Internet connection experienced by disabled students had also kept them in the dark even more.

\section{Lack of Confidence}

S1 '...I have no confidence that I will pass my exam if I sustain myself with online class...'

S2 '...hmmm I lost my ability when I was born and now I am losing my confidence level...'

S3 '...To be honest I have no confidence to attend online class and I think I will quit my degree studies...'

S4 '...I intend to stop my studies as I lost my confidence...'

S6 '... I tak yakin Mr (Not confidence)...'

$S 7$ '... I lost confidence and that is all I can say...'

From the above utterances, it was found that the disabled lacked confidence that had resulted from the online classes. They even felt like quitting from their courses, but this would adversely affect their future. From the interviews, it is evident that the online classes have seriously drained the confidence of the disabled students.

Due to their disabilities and the restrictions imposed on them, the disabled students are severely discouraged from attending classes and are not confident in themselves that they will be able to make it through the semester. This is caused by the lack of help and aid that they receive to cope with the new norm that they need to endure.

In addition, the present study was also triangulated by conducting semi-structured interviews with the lecturers, the education officers and CEOs and the parents. It was found that the disabled students were isolated, emotionally setback, exacerbated mental health, lacked confidence and anxiety. Responses from lecturers, parents and CEO were proof that they suffered these problems.

\section{Responses from the Lecturers are Summarised as follows}

.... they felt isolated, emotionally disturbed and it leads to mental health challenges and causes lots of anxiety...

A few lecturers from the public universities mentioned that each university has Disability Services Units (DSU) that plays a role in ensuring disabled students are not ignored and left behind. Several dissatisfactions were expressed by the students such as

Based on their dissatisfactions, lecturers have come up with suggestions and ways to accommodate the students such as providing videos that contain infographics that could aid students in learning. Furthermore, they also formed groups and teams to provide information for the students' special needs. In addition, they also contact the disabled students frequently to make sure everything is comfortable for them. The counselling departments were also urged to play their roles to motivate these students regularly. However, it was found that 
found that most of the disabled students had physiological impacts which caused stress, depression and mental illness especially when they faced technical difficulties regarding online classes. The universities should take responsibility to provide technical courses for the disabled students to ensure they are able to cope with online learning, having to use the online platforms more confidently. These measures would definitely reduce their level of anxiety and boost their confidence in managing their studies.

Responses from the Chief Executive Officers (CEOs) in Education are Summarised as follows: "...educational institutes have put in substantial effort to make sure the academic progress of disabled students is not impeded by the technological constraints. Online lessons are recorded so students can come back to a particular lesson to revise or to follow at their own pace. The education group CEOs are satisfied with their effort in helping disabled students overcome mental difficulties during the pandemic..."

From the findings of the study, we can determine that disabled students face seclusion, unstable emotions, aggravated mental state, anxiety and loss of confidence due to online education. As such, education group CEOs have taken several steps to help reduce the pressure on these students by implementing the following:

\section{Responses from the Parents are Summarised as follows:}

Many disabled students felt unhappy and were unwilling to talk about what they needed for their online studies such as electronic gadgets. One of the parents uttered:

'...the disabled students cannot be like this because you with disabilities in universities are considered to be still a new experience. You have to convince people about your needs...'

This statement is in line with the fact that students face isolation.

Furthermore, the parents voiced out,

"Another serious issue was the internet. Poor internet access was experienced during online classes, which included audio drop out or loss of sound and irregular internet connectivity. The lectures were at times unclear, which resulted in communication issues. These statements which frequently came from the lecturers during this time are stated as below;

'...voice is broken, it is not comprehended...'

'...could you please say it again? It was not heard...'

'...can you hear me? Could you hear my voice...?'

'...very few of your words can be heard...'

All these statements affected the disabled students, and they faced anxiety throughout the entire period.

'... a number of students had issues with their hardware. For instance, a few of them had defective microphones, which made sending voice transmissions difficult. Additionally, sometimes the computer would fail to boot, resulting in students being unable to follow the online classes. More hiccups happened in voice transmissions during the online session, and these interruptions produced stoppages in communication and caused unnecessary anxiety for the students. In view of the fact that the online class was not performed in the usual way, such as the face-to-face method, meant that students had issues trying to identify the person they were speaking to. Students posed questions such as "Whom am I speaking to right now?" and tried to figure out who the lecturer was...' 
Overall, the results indicated that the relevant Educational bodies were committed in solving the ensuing Internet problems to solve the students' difficulties. The lecturers understood the problems encountered by the students and they agreed that the resources would be improved so that the students' problems can be overcome. The improvements introduced to the online system may eventually provide better comprehension of the lectures. The parents lamented that the poor Internet connections had seriously impacted their disabled children. They suggested that more attention be devoted to improve the Internet system to create confidence among students. The parents felt that the new system of teaching and learning should be at least satisfactory so that students can continue their education without problems.

\section{Discussion}

The present study was designed to investigate the challenges faced by disabled students via online classes during the current pandemic. The findings of this study can be viewed from three perspectives namely disabled students, lecturers and parents.

From the disabled student's perspectives, they encountered numerous obstacles that ranged from poor Internet connectivity to personal health issues. They had been familiar with the traditional method of face-to face engagements with their lecturers. The sudden introduction of new platforms like the use of Zoom and Google Meet to deliver lectures were obstacles for which they were unprepared. They had not been given prior exposure to familiarize themselves with the transition from physical to online classes. As such they were psychologically affected which resulted in mental stress and emotional problems. The finding is in consensus with the study conducted by Loheswar (2020) that due to the online classes during the pandemic, the students had experienced some mental challenges.

The lecturers had to be familiar with new methods of delivering their lecturers that involved computer technology via the Internet within a short period of time. They were caught unaware and unprepared for this new system. They had to get quickly adjusted to gain the confidence of their students.

The parents were rather unhappy as the introduction of the Internet into the education system had created numerous problems for their disabled children. Their primary concern was the problem with the Internet connectivity that resulted in numerous problems for disabled students. The voices by the parents were similar to the study by Yao (2020) which states that the Internet connectivity was not favorable and caused interruptions.

Some examples of ways to ease the burden of the disabled students include the use of text-to-voice software, the use of more disabled-friendly electronics and more frequent communication between counsellors, students and parents, to ensure that they are able to cope with the situation.

\section{Implication of The Study}

Higher learning institutions in Malaysia have adopted e-learning as a viable alternative method to provide effective learning and teaching to students during the Covid-19 pandemic. However, disabled students, though being a minority group should not be excluded in receiving good e-learning output. As such, there is a need for universities to begin training lecturers who can later provide the necessary training to the disabled to be more proficient in using the various electronic platforms like Zoom, Skype, and Google Meet to overcome their learning challenges. The disabled need to be trained to overcome the ensuing technical issues that can physiologically impact their online learning abilities. On the other hand, 
universities also need to upgrade their computer technology to help disabled students. The stakeholders like lecturers, Education CEOs and parents need to play a supervisory role to understand the physiological state of the disabled so that necessary measures can be introduced to overcome their problems. The measures that have been introduced should be constantly scrutinized to alleviate the mental stress experienced by the disabled. Simultaneously, the lecturers should always be conscious of the necessities of the disabled and their involvement in these online classes. The attention given by the lecturers can make them feel they are not isolated and that can impact them emotionally and make them become more confident in their lessons.

\section{Conclusion}

Online learning conducted in institutions of higher learning during this Covid-19 pandemic should benefit all students. However, findings from this study reveal that the disabled faced many challenges which gave an impact on their mental and emotional health as they were unable to perform as well as their other counterparts in their learning process. Being a minority group, it is deemed necessary that their needs are also considered when online learning is conducted.

The results obtained from this study indicate that there is a need for universities to develop committees that can devote attention to disabled students. These committees can come up with specific guidelines for these disabled students and make the necessary recommendations to the academic staff who conduct the online classes, record lectures and various tests to consider these disabled students in the teaching-learning and assessment process.

There should also be some exemptions for those who are unable to participate in these online activities because of impending problems. The universities need to provide health assistance to protect the mental and emotional well-being of students by providing affordable health insurance that covers the mental problems and other unforeseen problems in the future. Online counselling opportunities should also be provided by universities for disabled students who encounter problems.

Other online facilities like admission and examination centres can be further improved to provide better access to disabled students. Future studies can be conducted to investigate the synchronous and asynchronous learning of the disabled using questionnaires. The results obtained can reveal the specific needs of the disabled. The results from these studies can also help lecturers of HLE to provide specific assistance to the disabled students rather than using the same materials that can trigger mental stress to them.

We can also conclude that the disabled students must overcome isolation, emotional setbacks, exacerbated mental health, anxiety, as well as the lack of confidence, in order to effectively adapt to the new learning environment to which they have been introduced. Some challenges related to the aforementioned topics include, intermittent internet connection, the lack of communication between the lecturers and students, the need to adapt to a completely new environment, not to mention the anxiety of facing an uncertain future.

In conclusion, disabled students require more help from their peers and lecturers to overcome the mental obstacles that they face. The quality of education, as well as electronics should be upgraded and improved to fit the needs of all students, whether disabled or not. There is a need to prepare pragmatic solutions to allow academics, teachers and facilitators to adapt comfortably to new norms in teaching and learning. 


\section{References}

Abdullah, S., Mansor, A. A, Napi, N. N. L. M., Mansor, W. N. W., Ahmed, A. N., Ismail, M., \& Ramly, Z.T. A. (2020). Air quality status during 2020 Malaysia Movement Control Order (MCO) due to 2019 novel coronavirus (2019-nCoV) pandemic. Sci. Total Environ, 7(29),15.

Ahmad, A. K., Norhunaini, M. S., Liyana, T., Muna, S., \& Syahrul, N. J. (2020). Transitioning to Online Learning during COVID-19 Pandemic: Case Study of a Pre-University Centre in Malaysia. International Journal of Advanced Computer Science and Applications,11(6), 217-223.

Al-Kumaim, N. H., Alhazmi, A. K., Mohammed, F., Gazem, N. A., Shabbir, M. S., Fazea, Y. (2021). Exploring the Impact of the COVID-19 Pandemic on University Students' Learning Life: An Integrated Conceptual Motivational Model for Sustainable and Healthy Online Learning. Sustainability, 13, 2-22.

Awani. (2020). Perutusan perdana menteri malaysia [Message from the Prime Minister of Malaysia] (video) (12:28) (in Malay). 13 March 2020. Retrieved 19 May, 2020 from Astro Awan. https://www.pmo.gov.my/PerutusanKhas050620.php

Bernama. (2020). Covid-19: PM outlines several key measures. Archived from the original on 14 March 2020. Retrieved 19 May, 2020 via Daily Express. https://www.dailyexpress.com.my/news/148684/covid-19-pm-outlines-several-keymeasures/

Buchanan, E. (1999). Assessment measures: Pre-tests for successful distance teaching and learning. Online Journal of Distance Learning Administration, 2(3), 112-133.

Brunvand, S., \& Abadeh, H. (2010). Making Online Learning Accessible. Intervention in School and Clinic, 45(5), 304-311.

Cavanaugh, C., Barbour, M., \& Clark, T. (2009). Research and practice in K-12 online learning: A review of open access literature. The International Review of Research in Open and Distance Learning, 10(1), 1-22.

Chu, A. M. Y., Liu, C. K. W., So, M. K. P., Lam, B. S. Y. (2021). Factors for Sustainable Online Learning in Higher Education during the COVID-19 Pandemic. Sustainability, 13(9), 2-16.

Creswell, J. (2018). Research design: Qualitative, quantitative, and mixed methods approaches (5th ed.) SAGE Publications, Inc.

Deci, E. L., \& Ryan, R. M. (1987). The support of autonomy and the control of behavior. Journal of Personality and Social Psychology, 53(6), 1024-1037.

Hill, J., \& Buerger, R. B. (1996). Hypermedia as a bridge between education and profession. Educational Technology Review, Winter (5), 21-25.

Holzer, J., Lüftenegger, M., Korlat, S., Pelikan, E., Salmela-Aro, K., Spiel, C., \&

Schober, B. (2021). Higher education in times of COVID-19: University students' basic need satisfaction, self-regulated learning, and well-being. AERA Open, 7(1), 1-13.

Lim, I. (2020). Reality for Malaysia's university students: Online learning challenges, stress, workload; possible solutions for fully digital future until Dec. Malay Mail. Retrieved 08 May, 2020, from https://www.malaymail.com/news/malaysia/2020/05/30/reality-formalaysias-university-students-online-learning-challenges-stress/1870717

Jonassen, D. H. (2005). Modeling with technology: Mindtools for conceptual change. (3rd Ed.). [Location: Publisher].

Leasure, A. R., Davis, L., \& Thievon, S. L. (2000). Comparison of student outcomes and preferences in a traditional vs. World Wide Web-based baccalaureate nursing research course. Journal of Nursing Education, 39(4), 149-154. 
Kesselman, M., \& Tobin, T. (1999). Evaluation of web-based library instruction programs. Eric Document Reproduction Services No. ED441454.

Kwesi, A. (2002). Web based instruction and students with learning disabilities: Examination of the strategies and limitations. Dissertation Abstracts International, 63(08) 2784A.

Krishnan, I., Mello, G., Kok, S., Sabapathy, S., Munian, S., Ching, H., Kandasamy, P.,

Ramalingam, S., Baskaran, S. and Kanan, V. (2020) "Challenges Faced by Hearing Impairment Students During COVID-19, Malaysian Journal of Social Sciences and Humanities (MJSSH), 5(8), pp. 106 - 116. doi: https://doi.org/10.47405/mjssh.v5i8.472.

Lockee, B. B. (2001), What matters in judging distance teaching? Not how much it's like a classroom course, The Chronicle of Higher Education. Retrieved June 30, 2020, from http://chronicle.com/article/What-Matters-in-Judging/108500/.

Miles, M. B., Huberman, A. M., \& Saldana, J. (2014). Qualitative data analysis: A method sourcebook, (3rd ed.) Washington, DC: Sage Publications.

Nieuwenhuis, F. J. (2010) From equality of opportunity to equality of treatment as a valuebased concern in education. In: Russo, C., Beckman JL and Jansen, J.D. (eds.) Equal Educational Opportunities: Comparative Perspectives in Education. Pretoria: Van Schaik

Norby, R. F., Pearce, K., \& Strand, S. (2000). Internet teaching by style: Profiling the on-line professor. Retrieved June 30, 2020, from http://ifets.massey.ac.nz/periodical/vol_2_2000/pearce.html.

O'Neil, C., \& Fisher, C. (2008). Should I take this course online? Journal of Nursing Education. 47(2), 53-59.

Rayyan, R. (2020). Special needs students face hurdles in e-learning. New Straits Times. Retrieved 08 May, 2021 https://www.nst.com.my/education/2020/05/590453/special-needs-students-facehurdles-e-learning

Smith, D. D. (1998). Introduction to special education: Teaching in the age of challenge (3rd ed.). Boston, MA: Allyn and Bacon.

Simoncelli, A., \& Hinson, J. M. (2008). College students with learning disabilities personal reactions to online learning. Journal of College Reading and Learning. Lenexa: 38(2), 49.

Sobia, S. S., Asif, A. S., Farzana, M., Atika, A. K., \& Arjumand, S. (2021). Online learning during the COVID-19 pandemic: Applying the self-determination theory in the 'new normal', Revista de Psicodidáctica (English ed.), 26(2), 168-177.

Thomas, K. F. C. (2021). Student engagement in K-12 online learning amid COVID-19: A qualitative approach from a self-determination theory perspective. Interactive Learning Environments, 1(2), 1-14.

Venezky, R. L., \& Davis, C. (2002). Que vademus? The transformation of schooling in a networked world. Research report: OECD/CERI.

Tan, V. (2021). IN FOCUS: Prolonged school closure in Malaysia due to COVID-19 shakes up learning experience. Channel New Asia. Retrieved 08 May, 2020, from https://www.channelnewsasia.com/news/asia/in-focus-malaysia-covid-19-schoolclosure-2020-parents-students-13740364

Viner, R. M., Russell, S. J., Croker, H., Packer, J., Ward, J., \& Stansfield, C., (2020). School closure and management practices during coronavirus outbreaks including COVID-19: A rapid systematic review. Lancet. Child Adolesc. 4, 397-404. doi: 10.1016/S23524642(20)30095-X

Ziadat A. H. (2019). The impact of e-learning in developing academic skills and social 
INTERNATIONAL JOURNAL OF ACADEMIC RESEARCH IN BUSINESS AND SOCIAL SCIENCES

Vol. 12, No. 1, 2022, E-ISSN: 2222-6990 @ 2022 HRMARS

interaction among students with learning disabilities in Jordan from the perspective of their teachers. TEM J, 8 1440-1448. 